\title{
METODOLOGIAS E TECNOLOGIAS PARA O ENSINO REMOTO EMERGENCIAL SUPERIOR
}

Semana Online Científica de Educação, 1a edição, de 25/10/2021 a 27/10/2021

ISBN dos Anais: 978-65-81152-18-5

\begin{abstract}
BACELLAR; Fernanda Losso ${ }^{1}$
\end{abstract}
\section{RESUMO}

No cenário da pandemia, exigiu-se o isolamento social, tendo como consequência a suspensão das aulas presenciais. Nesse contexto, no âmbito do ensino superior voltado ao ensino remoto emergencial (ERE), impulsionou-se o nascimento de novos paradigmas, modelos de ensinoaprendizado, e processos de comunicação educacional. Desse modo, foram implementadas estratégias didáticas, como a aplicação de metodologias ativas como elemento motivador no curso de Engenharia de Software, as quais foram utilizadas pelos docentes para dar continuidade aos semestres acadêmicos de forma remota. O estudo tem por objetivo geral analisar a implantação de metodologias ativas na prática da graduação no curso de Engenharia de Software voltado ao ensino remoto emergencial, avaliando o quanto o método está sendo eficiente em atingir os objetivos a que se propõe. Para tanto, foi utilizada uma pesquisa de natureza quantitativa. Os dados foram coletados por meio de questionário eletrônico, enviados aos graduandos do segundo semestre de um curso de Engenharia de Software. Os resultados e a análise demonstraram os desafios enfrentados para adaptação das metodologias ativas nas aulas de forma remota, no entanto_demonstrou resultados positivos, onde os alunos sentiram-se bastante interessados e motivados, e permitindo todo o contato com o conteúdo programado no plano de ensino da disciplina, mesmo com o isolamento social obrigatório vigente. Conclui-se assim, que a aplicação das metodologias ativas na educação superior no ensino remoto emergencial para que ocorra aprendizagem significativa é necessário o comprometimento na atuação dos principais envolvidos no processo educacional (discente e docente). Ao docente é necessário o empenho na elaboração de materiais e atividades instrucionais que sejam potencialmente significativas aos discentes.

PALAVRAS-CHAVE: ensino remoto emergencial, engenharia de software, ensino superior, metodologias ativas 